INTERVENTIONAL CARDIOLOGY AND SURGERY

\title{
Prosthetic valve endocarditis: who needs surgery? A multicentre study of 104 cases
}

\author{
G Habib, C Tribouilloy, F Thuny, R Giorgi, A Brahim, M Amazouz, J-P Remadi, G Nadji, \\ J-P Casalta, F Coviaux, J-F Avierinos, X Lescure, A Riberi, P-J Weiller, D Metras, D Raoult
}

Heart 2005;91:954-959. doi: 10.1136/hrt.2004.046177

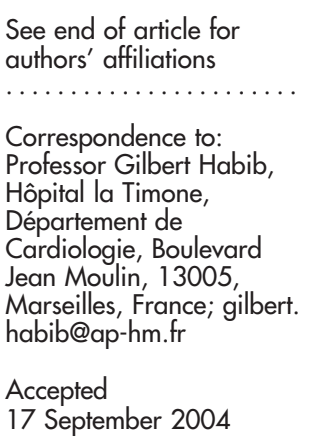

\begin{abstract}
Objectives: To identify the prognostic markers of a bad outcome in a large population of 104 patients with prosthetic valve endocarditis (PVE), and to study the influence of medical versus surgical strategy on outcome in PVE and thus to identify patients for whom surgery may be beneficial.

Design: Multicentre study.

Methods and results: Among 104 patients, $22(21 \%)$ died in hospital. Factors associated with in-hospital death were severe co-morbidity $(6 \%$ of survivors $v 41 \%$ of those who died, $p=0.05)$, renal failure $(28 \% \mathrm{v}$ $45 \%, p=0.05)$, moderate to severe regurgitation $(22 \% \vee 54 \%, p=0.006)$, staphylococcal infection $(16 \% \vee 54 \%, p=0.001)$, severe heart failure $(22 \% \vee 64 \%, p=0.001)$, and occurrence of any complication (60\% v 90\%, $p=0.05)$. By multivariate analysis, severe heart failure (odds ratio 5.5) and Staphylococcus aureus infection (odds ratio 6.1) were the only independent predictors of in-hospital death. Among 82 in-hospital survivors, 21 (26\%) died during a 32 month follow up. A Cox proportional hazards model identified early PVE, co-morbidity, severe heart failure, staphylococcus infection, and new prosthetic dehiscence as independent predictors of long term mortality. Mortality was not significantly different between surgical and non-surgical patients (17\% v 25\%, respectively, not significant). However, both in-hospital and long term mortality were reduced by a surgical approach in high risk subgroups of patients with staphylococcal PVE and complicated PVE.

Conclusions: Firstly, PVE not only carries a high in-hospital mortality risk but also is associated with high long term mortality and needs close follow up after the initial episode. Secondly, congestive heart failure, early PVE, staphylococcal infection, and complicated PVE are associated with a bad outcome. Thirdly, subgroups of patients could be identified for whom surgery is associated with a better outcome: patients with staphylococcal and complicated PVE. Early surgery is strongly recommended for these patients.
\end{abstract}

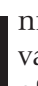
nfective endocarditis is the most serious complications of valve replacement and has been reported to occur in $1-6 \%$ of patients with valve prostheses. ${ }^{1}$ Despite improvements in medical treatment and surgery, prosthetic valve endocarditis (PVE) carries a high mortality risk ranging from $20-80 \%$ of affected patients. ${ }^{1}$ This unacceptably high mortality explains why several studies have tried to identify prognostic markers of bad outcome in these patients..$^{2-6}$ Unfortunately, most of these studies were limited by their retrospective nature, the lack of a uniform definition of PVE, and the small number of patients studied. In addition, the best treatment strategy for these patients is still debated. Although a surgical strategy is said to be the best treatment option, ${ }^{2}$ guidelines based on prospective randomised studies are still lacking ${ }^{7}$ and some authors claim that medical treatment can be sufficient for some patients. ${ }^{58}$

For these reasons, we performed a multicentre study whose objectives were, firstly, to identify the prognostic markers of a bad outcome in a large population of definite PVE; and, secondly, to study the influence of a medical versus a surgical strategy on outcome in PVE and thus to identify patients for whom surgery may be beneficial.

\section{PATIENTS AND METHODS \\ Patients}

From January 1991 to March 2003, 104 consecutive patients from two centres fulfilled the Duke criteria ${ }^{9}$ for PVE (71 men and 33 women, mean (SD) age 60 (16) years) and formed our study population. All these patients underwent blood culture and systematic transthoracic and transoesophageal studies, as previously reported. ${ }^{10}$ All patients were scheduled for a 4-6 week antibiotic regimen. The use of surgery was based on the clinical judgment of the patient's physician and was retrospectively tabulated.

During the same period, 250 valves were replaced each year in each centre, giving an incidence of about $2 \%$. Among these patients, 20 (19\%) had early and 84 (81\%) had late endocarditis. However, since ours are tertiary referral centres, some patients with PVE came from other centres from our country; thus, the number of cases of PVE reported in this study does not exactly reflect the true incidence of infective endocarditis complicating valve replacement in our centres. On the other hand, during the same period, 515 patients with infective endocarditis were admitted to our two centres. Thus, PVE accounts for $20 \%$ of all cases of infective endocarditis treated in our centres.

\section{Definitions and end points}

For each patient, the following parameters were analysed: fever; new or changing murmur; presence of co-morbidity (diabetes, age $>75$, HIV infection, cancer, immunodepression); immunological manifestations (Osler's nodes, Roth spots); biological markers (anaemia (haemoglobin $<6.2 \mathrm{mmol} / \mathrm{l}$ ), leucocytosis (white cell count $\left.>10^{9} / \mathrm{l}\right)$ ); $\mathrm{C}$ reactive protein $>5 \mathrm{mg} / \mathrm{l}$; renal failure (serum creatinine $>177 \mu \mathrm{mol} / \mathrm{l}$ ); delay to diagnosis, defined as a delay between the onset of symptoms and correct diagnosis; echographic parameters (presence, size, and mobility of vegetations, presence of abscesses, pseudoaneurysm of fistula); and results of blood cultures. 
A diagnosis of PVE was based on a strict case definition, in the presence of surgical confirmation or definite endocarditis by the Duke criteria. ${ }^{2}$ PVE occurring during the first 12 months after surgery was called early PVE and PVE occurring after 12 months was called late endocarditis. ${ }^{11-13}$

Major complications occurring during acute infective endocarditis were embolic events (based on clinical signs and data derived from non-invasive diagnostic procedures), new prosthetic dysfunction, congestive heart failure (New York Heart Association classes III-IV), abscess formation detected by echocardiography or surgery, and severe ECG conduction abnormalities. The presence of one or more of these complications defined "complicated PVE". ${ }^{4}$

Major end points were the need for surgery, recurrence or relapse of PVE, and death. A recurrent episode of valve infection was defined as a relapse if infection occurred in the 12 months after hospital discharge and was caused by the same organism as originally and was defined as recurrent in other cases. ${ }^{3}$ In-hospital mortality was defined as death occurring during the initial hospitalisation for infective endocarditis.

\section{Surgical management}

Surgery was performed in 51 patients $(49 \%)$. The indications for surgery were severe prosthetic dysfunction in 11 (22\%) patients, severe heart failure in 17 (33\%), large persistent vegetation after systemic embolisation in $15(29 \%)$, and abscess or perivalvar involvement in $29(57 \%)$. Of these 51 surgical patients, 27 (53\%) underwent surgery within the first 15 days after the diagnosis of infective endocarditis.

Surgical interventions were performed by four surgeons (two in each centre) and the surgical management was not standardised. However, as the surgical experience increased, operative technique evolved, with more radical debridement of cardiac tissue and more frequent use of homograft valves in the aortic position, when this substitute was available. Aortic root homograft replacement was the preferred technique for patients with PVE and abscess formation. Surgery consisted of valve replacement with a bioprosthesis in 19 patients, with a mechanical valve in 15 patients, and with a homograft in 17 patients.

\section{Statistical analysis}

All data were analysed with a commercially available package (SPSS for Windows, rel 10.0, 1999; SPSS Inc, Chicago,

Table 1 Clinical and laboratory findings in 104 patients with prosthetic valve endocarditis (PVE)

\begin{tabular}{|c|c|c|c|c|}
\hline & $\begin{array}{l}\text { All } \\
\text { patients } \\
(n=104)\end{array}$ & $\begin{array}{l}\text { Early } \\
\text { group } \\
(n=20)\end{array}$ & $\begin{array}{l}\text { Late } \\
\text { group } \\
(n=84)\end{array}$ & p Value \\
\hline Age (years) & $60(16)$ & $57(18)$ & $62(15)$ & 0.19 \\
\hline Men & $70(67 \%)$ & $13(65 \%)$ & $57(68 \%)$ & 0.72 \\
\hline \multicolumn{5}{|l|}{ Type of valve } \\
\hline Bioprosthetic & $60(57 \%)$ & $7(35 \%)$ & $53(64 \%)$ & \\
\hline Mechanical & $39(37 \%)$ & $10(50 \%)$ & $29(34 \%)$ & 0.016 \\
\hline Homograft & $5(5 \%)$ & $3(15 \%)$ & $2(2 \%)$ & \\
\hline \multicolumn{5}{|l|}{ Valve location } \\
\hline Mitral & $36(35 \%)$ & $8(40 \%)$ & $28(34 \%)$ & 0.6 \\
\hline Aortic & $68(65 \%)$ & $12(60 \%)$ & $56(66 \%)$ & 0.6 \\
\hline Co-morbidity $\geqslant 1$ & $55(53 \%)$ & $11(55 \%)$ & $44(53 \%)$ & 0.83 \\
\hline Co-morbidity $\geqslant 2$ & $14(13 \%)$ & $3(15 \%)$ & $11(13 \%)$ & 1 \\
\hline Fever & $99(95 \%)$ & $19(95 \%)$ & $80(96 \%)$ & 1 \\
\hline New or changing murmur & $46(44 \%)$ & $9(45 \%)$ & $37(46 \%)$ & 0.95 \\
\hline Osler's nodes, Janeway & $3(3 \%)$ & $1(5 \%)$ & $2(2 \%)$ & 1 \\
\hline NYHA III-IV & $32(31 \%)$ & $7(35 \%)$ & $25(30 \%)$ & 0.65 \\
\hline Renal failure & $33(32 \%)$ & $6(30 \%)$ & $27(32 \%)$ & 0.86 \\
\hline Leucocytosis $>10^{9} / \mathrm{I}$ & $46(44 \%)$ & $13(65 \%)$ & $33(30 \%)$ & 0.008 \\
\hline Anaemia $(\mathrm{Hb}<6.2 \mathrm{mmol} / \mathrm{l})$ & $38(37 \%)$ & $3(15 \%)$ & $35(42 \%)$ & 0.046 \\
\hline
\end{tabular}

Illinois, USA). Variable findings between groups were compared by the $\chi^{2}$ test. Fisher's exact test (two tailed) was used if the expected count in any cell was $<5$. In addition, a multivariate analysis was performed with a forward stepwise logistic regression with $p=0.10$ as the threshold for entering or removing variables. The logistic regression model was elaborated from variables identified by univariate analysis and from a priori selected variables (surgery, early surgery, embolic events, cerebral embolism, abscess, presence of vegetation, Streptococcus bovis, and Staphylococcus aureus). For evaluation of long term mortality, independent predictors were identified by multivariate analysis in a Cox proportional hazards model. The KaplanMeier method and survival curves were tested with the log rank test.

\section{RESULTS}

\section{Clinical and laboratory findings}

Table 1 shows clinical and laboratory findings in the 104 patients with PVE. During the study period, 20 patients had early and 84 patients had late endocarditis. The location of PVE was mitral and aortic in 35\% and 65\%, respectively. Mechanical PVE was more frequent in the early group and bioprosthetic PVE was more frequent in late PVE. Other clinical features were similar between groups but more patients in the early group had increased white cell counts and more in the late group had anaemia (table 1).

\section{Duke criteria for endocarditis}

Vegetations and abscesses were observed in $61 \%$ and $51 \%$ of patients with PVE, respectively, without significant differences between early and late PVE (table 2). Among microorganisms involved, streptococci were observed most often in late PVE (38\%) and S aureus was the most frequent in early PVE (35\%) (table 2 ).

\section{Complications and outcome}

Table 3 summarises the complications and outcomes in PVE. Embolic events occurred in 35 (33\%) patients. The incidence of this and other complications was similar between early and late PVE. Early surgery was more often needed in the early group than in the late group ( $80 \% \vee 41 \%$, respectively).

Among 104 patients, $22(21 \%)$ died in hospital. Causes of death were multiorgan failure in 10 patients, uncontrolled infection in three, congestive heart failure or cardiogenic shock in six, and cerebral haemorrhage in three. Recurrent PVE was observed in only five patients during follow up.

Among 82 in-hospital survivors, 21 (26\%) died during a mean 32 months' follow up (table 3). Causes of late death were congestive heart failure in nine patients, myocardial infarction in three, cancer in one, gastrointestinal bleeding in one, hepatic failure in one, recurrent endocarditis in two, and unknown in four. Cumulative mortality was higher in early than in late PVE $(65 \% \vee 36 \%$, respectively, $p=0.01)$. After a mean 32 months' follow up, only 61 (58\%) patients were still alive.

Factors affecting in-hospital and long term mortality Table 4 summarises the influence of clinical, biological, echographic, and bacteriological factors on survival. By univariate analysis, factors associated with in-hospital mortality were severe co-morbidity $(\mathrm{p}=0.05)$, renal failure $(p=0.05)$, moderate to severe regurgitation $(p=0.006)$, staphylococcal infection $(p=0.001)$, severe heart failure $(\mathrm{p}=0.001)$, and occurrence of any complication $(\mathrm{p}=0.05)$. By multivariate analysis (logistic regression analysis) (table 5), severe heart failure (odds ratio (OR) 5.5, 95\% confidence interval (CI) 1.9 to 16.1 ) and $S$ aureus 
Table 2 Duke major criteria for endocarditis in 104 patients

\begin{tabular}{|c|c|c|c|c|}
\hline & $\begin{array}{l}\text { All patients } \\
\text { ( } n=104)\end{array}$ & $\begin{array}{l}\text { Early group } \\
(n=20)\end{array}$ & $\begin{array}{l}\text { Late group } \\
(\mathrm{n}=84)\end{array}$ & $\mathrm{p}$ Value \\
\hline Positive echocardiogram & 97 (93\%) & $19(95 \%)$ & $78(93 \%)$ & 0.7 \\
\hline Vegetation & $64(61 \%)$ & $14(70 \%)$ & $50(60 \%)$ & 0.42 \\
\hline Abscess & $53(51 \%)$ & $13(65 \%)$ & $40(48 \%)$ & 0.17 \\
\hline New prosthetic valve dehiscence & 31 (30\%) & $6(30 \%)$ & $25(30 \%)$ & 0.99 \\
\hline Positive blood culture & $79(76 \%)$ & $14(70 \%)$ & $65(78 \%)$ & 0.62 \\
\hline All streptococci & $34(33 \%)$ & $2(10 \%)$ & $32(38 \%)$ & 0.015 \\
\hline Streptococcus bovis & $10(10 \%)$ & $1(5 \%)$ & $9(11 \%)$ & 0.71 \\
\hline Enterococci & $12(12 \%)$ & 0 & $12(14 \%)$ & 0.15 \\
\hline Streptococcus viridans & $12(12 \%)$ & $1(5 \%)$ & $11(13 \%)$ & 0.52 \\
\hline All staphylococci & $25(24 \%)$ & $8(40 \%)$ & $17(20 \%)$ & 0.12 \\
\hline Staphylococcus aureus & $21(20 \%)$ & $7(35 \%)$ & $14(17 \%)$ & 0.13 \\
\hline Others (coagulase negative) & $4(4 \%)$ & $1(5 \%)$ & $3(4 \%)$ & 1 \\
\hline \multicolumn{5}{|l|}{ Others } \\
\hline Q fever & $2(2 \%)$ & 0 & $2(2 \%)$ & 0.48 \\
\hline Candida species & $3(3 \%)$ & 0 & $3(4 \%)$ & 0.9 \\
\hline HACEK & $2(2 \%)$ & 0 & $2(2 \%)$ & 1 \\
\hline Others & $13(12 \%)$ & $4(20 \%)$ & $9(11 \%)$ & 0.7 \\
\hline
\end{tabular}

infection (OR 6.1, 95\% CI 1.9 to 19.2) were the only independent predictors of in-hospital death.

A Cox proportional hazards model identified early PVE, comorbidity, severe heart failure, staphylococcus infection, and new prosthetic dehiscence as independent predictors of long term mortality (table 5).

\section{Influence of surgery}

Fifty one $(49 \%)$ patients underwent surgery during the active phase of endocarditis. For the whole population of patients with PVE, in-hospital mortality was not significantly different between surgical and non-surgical patients (17\% v 25\%, respectively, not significant). However, among 25 patients with staphylococcal PVE, in-hospital mortality was lower in surgical than in non-surgical patients $(27 \% \quad v \quad 73 \%$, $p=0.03)$. Long term mortality was also lower in staphylococcal PVE treated surgically than in the medical group $(\mathrm{p}=0.03)$ (fig $\mathrm{lA})$.

Similarly, among 69 patients with complicated PVE, inhospital mortality was lower in 44 surgical patients (eight deaths; 18\%) than in 25 non-surgical patients (12 deaths; $48 \%, \mathrm{p}=0.05)$. Conversely, in-hospital mortality was low in the remaining 35 patients with non-complicated PVE, either surgically (no deaths among seven patients) or medically treated (two deaths among 28 patients; 7\%). Findings were similar concerning long term survival in these patients, long term mortality being lower in surgical patients only in complicated PVE $(p=0.001)$ (fig 1B).

\section{DISCUSSION}

This study is the largest published series of strict cases of PVE as defined by the Duke criteria. Our series not only confirmed the high in-hospital mortality risk in these patients but also showed that this risk persists during late follow up. In addition, markers of both short and long term mortality were identified and subgroups which benefit from surgery were defined.

\section{Prognostic factors in PVE}

PVE is still associated with a very high mortality and the best treatment option for these patients is still debated. Thus, better identification of predictors of outcome is required. Several studies tried to identify prognostic factors in PVE but their results are conflicting. The reasons for these conflicting results include the small number of patients in some studies, the lack of uniform definition of PVE in the oldest series, the absence of transoesophageal echographic study in most of the oldest series, and the retrospective nature of all of these studies.

\section{Complicated PVE}

Among the prognostic factors, the presence of complications of PVE are clearly associated with a higher mortality. In the series of Calderwood and colleagues, ${ }^{3} 116$ patients with PVE were studied with a $23 \%$ mortality rate. Patients with PVE complicated by new prosthetic regurgitation, heart failure, persistent fever under treatment, and new abnormalities of cardiac conduction had a higher mortality than patients with

Table 3 Complications and outcomes

\begin{tabular}{lllll}
\hline & $\begin{array}{l}\text { All patients } \\
(\mathbf{n = 1 0 4 )}\end{array}$ & $\begin{array}{l}\text { Early group Late group } \\
(\mathbf{n = 2 0 )}\end{array}$ & $\begin{array}{l}\text { (n=84) } \\
\text { p Value }\end{array}$ \\
\hline Embolic events & $35(33 \%)$ & $6(30 \%)$ & $29(35 \%)$ & 0.67 \\
Cerebral haemorrhage & $5(5 \%)$ & $2(10 \%)$ & $3(4 \%)$ & 0.51 \\
Severe heart failure & $32(31 \%)$ & $7(35 \%)$ & $25(30 \%)$ & 0.65 \\
High level conduction abnormality & $6(6 \%)$ & $1(5 \%)$ & $5(6 \%)$ & 1 \\
Surgery (active phase $<30$ days) & $51(49 \%)$ & $16(80 \%)$ & $35(41 \%)$ & 0.001 \\
In-hospital mortality & $22(21 \%)$ & $6(30 \%)$ & $16(19 \%)$ & 0.43 \\
$\quad$ After surgery in active phase & $9(17 \%)$ & $5(31 \%)$ & $4(11 \%)$ & 0.16 \\
$\quad$ After medical treatment in active phase & $13(25 \%)$ & $1(25 \%)$ & $12(25 \%)$ & 1 \\
Late mortality & $21 / 82(26 \%)$ & $7(50 \%)$ & $14(20 \%)$ & 0.07 \\
Cumulated long term mortality & $43(41 \%)$ & $13(65 \%)$ & $30(36 \%)$ & 0.01 \\
Relapse and reinfections & $5(5 \%)$ & $1(6 \%)$ & $4(5 \%)$ & 1 \\
\hline
\end{tabular}


Table 4 Factors affecting mortality

\begin{tabular}{|c|c|c|c|c|c|c|c|}
\hline \multirow[b]{2}{*}{ Factor } & \multirow{2}{*}{$\begin{array}{l}\text { All patients } \\
(n=104)\end{array}$} & \multicolumn{3}{|c|}{ In-hospital mortality } & \multicolumn{3}{|l|}{ Total mortality } \\
\hline & & Alive $(n=82)$ & Dead ( $n=22)$ & $p$ Value & Alive $(n=61)$ & Dead $(n=43)$ & p Value \\
\hline \multicolumn{8}{|l|}{ Clinical factors } \\
\hline Age (years) & $60(16)$ & $60(15)$ & $63(16)$ & 0.2 & $58(15)$ & $62(17)$ & 0.25 \\
\hline Men & $70(67 \%)$ & $56(68 \%)$ & $14(63 \%)$ & 0.41 & $43(70 \%)$ & 27 (63\%) & 0.29 \\
\hline Early PVE & $20(19 \%)$ & $14(17 \%)$ & $6(27 \%)$ & 0.22 & $7(11 \%)$ & $13(30 \%)$ & 0.01 \\
\hline Late PVE & $84(81 \%)$ & $68(83 \%)$ & $16(73 \%)$ & & $54(89 \%)$ & $30(70 \%)$ & \\
\hline Co-morbidity & $55(53 \%)$ & $46(56 \%)$ & $9(40 \%)$ & 0.36 & $30(49 \%)$ & $25(58 \%)$ & 0.39 \\
\hline$>1$ co-morbidity & $14(13 \%)$ & $5(6 \%)$ & $9(41 \%)$ & 0.05 & $5(8 \%)$ & $9(21 \%)$ & 0.07 \\
\hline \multicolumn{8}{|l|}{ Type of valve } \\
\hline Bioprosthetic & $60(57 \%)$ & $48(58 \%)$ & $12(54 \%)$ & & $37160 \%$ & $23(54 \%)$ & \\
\hline Mechanical & $39(37 \%)$ & $30(37 \%)$ & $9(41 \%)$ & 0.92 & $20(33 \%)$ & $19(44 \%)$ & 0.32 \\
\hline Homograft & $5(5 \%)$ & $4(5 \%)$ & $1(5 \%)$ & & $4(7 \%)$ & $1(2 \%)$ & \\
\hline \multicolumn{8}{|l|}{ Valve location } \\
\hline Mitral & $36(35 \%)$ & $27(33 \%)$ & $9(41 \%)$ & 0.33 & $18(30 \%)$ & $18(42 \%)$ & 0.12 \\
\hline Atrial & $68(65 \%)$ & $55(67 \%)$ & $13(59 \%)$ & & $43(70 \%)$ & $25(58 \%)$ & \\
\hline \multicolumn{8}{|l|}{ Biological factors } \\
\hline Renal failure & $33(32 \%)$ & $23(28 \%)$ & $10(45 \%)$ & 0.05 & $17(35 \%)$ & $16(51 \%)$ & 0.13 \\
\hline Leucocytosis (>109/I) & $46(44 \%)$ & $42(51 \%)$ & $4(18 \%)$ & 0.32 & $29(56 \%)$ & $17(61 \%)$ & 0.85 \\
\hline \multicolumn{8}{|l|}{ Echocardiographic factors } \\
\hline Vegetation & $64(61 \%)$ & $48(58 \%)$ & $16(72 \%)$ & 0.55 & $31(49 \%)$ & $33(72 \%)$ & 0.03 \\
\hline Vegetation $>10 \mathrm{~mm}$ long & $32(31 \%)$ & $25(30 \%)$ & $7(31 \%)$ & 0.94 & $16(26 \%)$ & $16(35 \%)$ & 0.42 \\
\hline Highly mobile vegetation & $47(45 \%)$ & $34(41 \%)$ & $13(59 \%)$ & 0.25 & $21(34 \%)$ & $26(60 \%)$ & 0.02 \\
\hline Abscess & $53(51 \%)$ & $42(51 \%)$ & $11(50 \%)$ & 0.69 & $31(51 \%)$ & $22(53 \%)$ & 0.79 \\
\hline New prosthetic valve dehiscence & $31(30 \%)$ & $22(27 \%)$ & $9(41 \%)$ & 0.28 & $13(21 \%)$ & $18(42 \%)$ & 0.03 \\
\hline Moderate or severe regurgitation & $30(29 \%)$ & $18(22 \%)$ & $12(54 \%)$ & 0.006 & $12(20 \%)$ & $18(42 \%)$ & 0.02 \\
\hline \multicolumn{8}{|l|}{ Microbiological } \\
\hline Positive blood cultures & $79(76 \%)$ & $61(74 \%)$ & $18(81 \%)$ & 0.84 & $48(79 \%)$ & $31(72 \%)$ & 0.41 \\
\hline$S$ bovis & $10(10 \%)$ & $9(11 \%)$ & $1(5 \%)$ & 0.56 & $8(13 \%)$ & $2(5 \%)$ & 0.35 \\
\hline Enterococci & $12(12 \%)$ & $9(11 \%)$ & $3(14 \%)$ & 0.95 & $7(11 \%)$ & $5(11 \%)$ & 0.95 \\
\hline$S$ viridans & $12(12 \%)$ & $12(15 \%)$ & 0 & 0.11 & $11(18 \%)$ & $1(2 \%)$ & 0.01 \\
\hline All staphylococci & $25(24 \%)$ & $13(16 \%)$ & $12(54 \%)$ & $<0.001$ & $10(17 \%)$ & $15(35 \%)$ & 0.07 \\
\hline$S$ aureus & $21(20 \%)$ & $10(12 \%)$ & $11(50 \%)$ & 0.001 & $7(11 \%)$ & $14(32 \%)$ & 0.02 \\
\hline Q fever & $2(2 \%)$ & $2(3 \%)$ & 0 & 1 & $2(3 \%)$ & 0 & 0.61 \\
\hline Candida species & $3(3 \%)$ & $3(4 \%)$ & 0 & 0.81 & $1(2 \%)$ & $2(5 \%)$ & 0.79 \\
\hline HACEK & $2(2 \%)$ & $2(3 \%)$ & 0 & 1 & $2(3 \%)$ & 0 & 0.61 \\
\hline \multicolumn{8}{|l|}{ Complications } \\
\hline Embolic event & $35(33 \%)$ & $26(32 \%)$ & $9(41 \%)$ & 0.58 & $20(32 \%)$ & $15(35 \%)$ & 0.95 \\
\hline Cerebral haemorrhage & $5(5 \%)$ & $2(3 \%)$ & $3(14 \%)$ & 0.12 & $2(3 \%)$ & $3(7 \%)$ & 0.73 \\
\hline Severe heart failure & $32(31 \%)$ & $18(22 \%)$ & $14(64 \%)$ & 0.001 & $10(16 \%)$ & $22(51 \%)$ & $<0.001$ \\
\hline High level conduction abnormality & $6(6 \%)$ & $4(5 \%)$ & $2(9 \%)$ & 0.87 & $4(6 \%)$ & $2(5 \%)$ & 0.96 \\
\hline Any complication & $69(66 \%)$ & $49(60 \%)$ & $20(90 \%)$ & 0.05 & $35(57 \%)$ & $34(79 \%)$ & 0.05 \\
\hline Early surgery ( < 30 days) & $51(49 \%)$ & $42(51 \%)$ & $9(41 \%)$ & 0.8 & $31(51 \%)$ & $20(46 \%)$ & 0.79 \\
\hline
\end{tabular}

uncomplicated infection (OR 6.4). Aortic valve infection and early ( $<12$ months) PVE were associated with an increased risk of complicated PVE. John and colleagues ${ }^{4}$ studied 33 cases of $S$ aureus PVE; they confirmed that the presence of complicated PVE, including abscess formation, was the unique predictor of death with an odds ratio of 13.7.

\section{Staphylococcal PVE and early PVE}

$S$ aureus infection and early PVE were also associated with an increased mortality. In the recent series of Akowuah and

\begin{tabular}{|c|c|c|c|}
\hline \multirow[b]{2}{*}{ Predictors of in-hospital mortality } & \multicolumn{3}{|c|}{ Logistic regression analysis } \\
\hline & p Value & $\begin{array}{l}\text { Adjusted } \\
\text { OR }\end{array}$ & $95 \% \mathrm{Cl}$ \\
\hline \multirow{3}{*}{$\begin{array}{l}\text { Severe heart failure } \\
S \text { aureus }\end{array}$} & 0.002 & 5.5 & 1.9 to 16.1 \\
\hline & 0.002 & 6.1 & 1.9 to 19.2 \\
\hline & \multicolumn{3}{|c|}{ Cox proportional hazards model } \\
\hline Predictors of long term mortality & RR & $95 \% \mathrm{Cl}$ & p Value \\
\hline Early PVE & 2.14 & 1.08 to 4.25 & 0.03 \\
\hline Co-morbidity & 3 & 1.36 to 6.61 & 0.006 \\
\hline Severe heart failure & 4.19 & 2.18 to 8.03 & $<0.0001$ \\
\hline Staphylococcus infection & 2.01 & 1.01 to 4.02 & 0.007 \\
\hline New prosthetic dehiscence & 2.43 & 1.27 to 4.65 & 0.007 \\
\hline
\end{tabular}

colleagues, ${ }^{5}$ the only predictor of late death by multivariate analysis was early PVE. In another series ${ }^{2}$ of 59 cases of late PVE, in-hospital mortality was $25 \%$; after adjustment for age and type of prosthesis, multiple logistic regression produced an odds ratio for death from non-streptococcal infections of 9.67. Similar results were obtained by Wolff and colleagues. ${ }^{6}$ In their series of 122 patients with PVE, the four month mortality was $34 \%$ and $S$ aureus was the main predictor of death (75\% $\vee 15 \%$ with other pathogens). Other prognostic factors identified by this study were prothrombin time $<30 \%$, mediastinitis, heart failure, septic shock, and renal failure.

Our study identified severe heart failure, staphylococcal infection, and complicated PVE as markers of both inhospital and late mortality and clearly showed that severe heart failure and S aureus infection were the only independent predictors of in-hospital death. In addition, other markers such as co-morbidity and early PVE were identified as independent prognostic markers of late death. These results mean that a subset of patients with PVE-that is, patients with early staphylococcal PVE and patients with complicated PVE—-must be managed aggressively.

\section{Treatment options and influence of surgery on} outcome

Operative mortality is high in PVE, ranging from $10-50 \%$ in past studies, ${ }^{14}$ and is the highest mortality among repeat operations for prosthetic dysfunction, ${ }^{15}$ even with the use of 

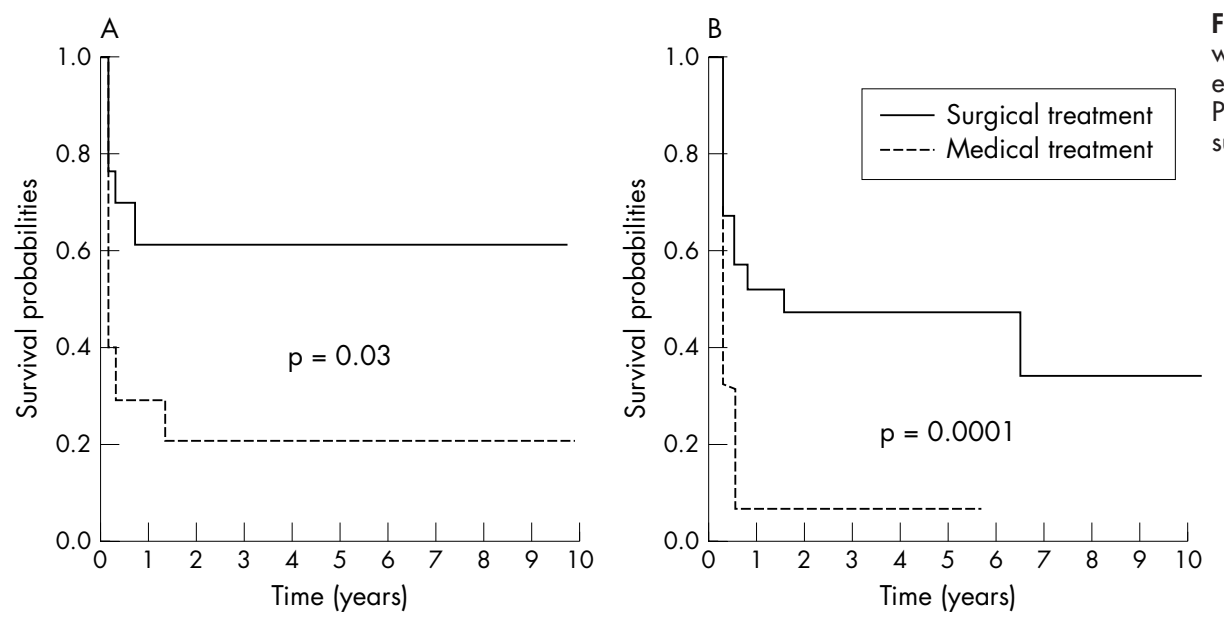

Figure 1 Long term survival of patients with (A) staphylococcal prosthetic valve endocarditis (PVE) and (B) complicated PVE treated either medically or surgically. homograft aortic root replacement. ${ }^{16}$ However, mortality seems to be lower in the most recent series. ${ }^{11}{ }^{17}$ Our inhospital mortality of $17 \%$ after surgery is in the range of mortality observed in the most recent series. ${ }^{21}$

The optimal treatment strategy in PVE is still debated. Although surgery is considered the best option when PVE causes severe prosthetic dysfunction or heart failure, current recommendations are not based on prospective randomised studies and the best treatment for PVE in the absence of such complications is still debated. Surgery is the treatment of choice of PVE for some authors ${ }^{3}$ but others ${ }^{8}$ think that antibiotics may be sufficient for some patients. Yu and colleagues $^{18}$ followed up 74 patients with PVE for one year and found a higher mortality in medically than in surgically treated patients $(56 \% v 23 \%)$. Others obtained similar results. ${ }^{3} 46151719$

On the other hand, John and colleagues ${ }^{4}$ found surgery to reduce mortality in patients with $S$ aureus PVE, even in the absence of cardiac complications. However, a recent multicentre study ${ }^{20}$ showed that surgery was probably not necessary for all of these patients.

Lastly, all previous studies were limited by their retrospective nature, the non-uniform definition of PVE, and the small number of patients studied. More important, a limitation of most of these studies is that the most severely ill patients who were not considered good candidates for surgery because of a poor general condition were included in the medical group, thus potentially causing selection bias. For example, in the study of Gordon and colleagues, ${ }^{17}$ although surgery was associated with improved long term survival when compared with treatment with antibiotics alone $(61 \% v$ $32 \%$ at three years), patients judged to be too ill to survive surgery accounted for almost two thirds of the patients treated medically. So, in the absence of studies prospectively designed to compare medical versus surgical treatment, caution is needed in interpreting treatment results.

In our study, early PVE, complicated PVE, and staphylococcal PVE were identified as markers of bad short term and long term prognoses. More importantly, patients for whom early surgery would be associated with a better outcome were clearly identified, and included patients with staphylococcal PVE and complicated PVE. These results are in agreement with the recently published guidelines of the European Society of Cardiology, which recommend surgery for active PVE in case of early and complicated PVE, particularly if staphylococci are the infecting agents. ${ }^{21}$

Identification of patients who can be treated by antibiotics alone has been attempted, ${ }^{58}$ but the number of patients studied in those series were limited and selection criteria are still discussed. ${ }^{22}$ Conservative treatment has been proposed for patients with non-staphylococcal PVE without complication $^{68}$ especially for patients with late bioprosthetic endocarditis. In our series, however, we observed no difference in prognosis between patients with bioprosthetic or with mechanical PVE. In addition, although in-hospital mortality was relatively low in our series, a significant number of hospital survivors died during the mid-term follow up. Thus, if an initial medical option is chosen, these patients need close clinical and echographic follow up because of the potential risk of late complication and recurrent PVE. ${ }^{3}$

\section{Study limitations}

Several limitations of our study have to be outlined. Firstly, the main limitation is that it was a retrospective nonrandomised study. Secondly, our study was performed in referral centres, which may introduce a referral bias into our results. Thirdly, a bias against surgery in our study is probable as in other past studies, as some patients judged too sick for surgery were included in the medical group. Conversely, a bias to surgery also exists, particularly for patients with large vegetations, staphylococcal infection, or annular abscess, as those patients more often undergo surgery. However, if staphylococcal infection was associated with a higher mortality, statistical analysis did not show that the incidence of surgery or death was significantly influenced by the presence of an abscess or by the size and mobility of the vegetations. Another potential limitation of the study is that surgeons may differ significantly concerning intraoperative management and that these differences may affect outcome. To specifically address the effects of this possible bias, a statistical analysis was performed and showed no significant difference in terms of survival either between surgeons or between the two centres. Lastly, the decision to operate or not was not randomised but was based on the clinical judgment of the physician and the surgical team; thus, the true impact of surgery is difficult to assess.

However, and despite these limitations, because the results of past studies were conflicting, because the number of published series of a large number of patients with PVE are very few, and because studies in this setting will probably never be randomised, we believe that our results are sufficient to strongly recommend surgery for patients with complicated PVE and staphylococcal PVE.

\section{Conclusions and clinical implications}

PVE not only carries a high in-hospital mortality risk but also is associated with high long term mortality and needs close follow up after the initial episode. Congestive heart failure, 
early PVE, staphylococcal infection, and complicated PVE are associated with a bad outcome. Our study enabled us to identify subgroups of patients for whom surgery is associated with a better outcome: patients with staphylococcal and complicated PVE. Early surgery is strongly recommended for these patients.

\section{Authors' affiliations}

G Habib, F Thuny, R Giorgi, M Amazouz, J-P Casalta, J-F Avierinos, A Riberi, P-J Weiller, D Metras, D Raoult, Department of Cardiology, La Timone Hospital, Marseilles, France

C Tribouilloy, A Brahim, J-P Remadi, G Nadji, F Coviaux, X Lescure, CHU SUD Department of Cardiology, Amiens, France

No financial disclosure

No conflict of interest

\section{REFERENCES}

1 Vongpatanasin W, Hillis LD, Lange RA. Prosthetic heart valves. N Engl J Med 1996;335:407-16.

2 Tornos P, Almirante B, Olona $M$, et al. Clinical outcome and long-term prognosis of late prosthetic valve endocarditis: a 20-year experience. Clin Infect Dis 1997:24:381-6.

3 Calderwood SB, Swinski LA, Karchmer AW, et al. Prosthetic valve endocarditis: analysis of factors affecting outcome of therapy. J Thorac Cardiovasc Surg 1986;92:776-83.

4 John MDV, Hibberd PL, Karchmer AW, et al. Staphylococcus aureus prosthetic valve endocarditis: optimal management and risk factors for death. Clin Infect Dis 1998;26:1302-9.

5 Akowuah EF, Davies W, Oliver S, et al. Prosthetic valve endocarditis: early and late outcome following medical or surgical treatment. Heart 2003:89:269-72

6 Wolff M, Witchitz S, Chastang C, et al. Prosthetic valve endocarditis in the ICU: prognostic factors of overall survival in a series of 122 cases and consequences for treatment decision. Chest 1995;108:688-94.
7 Bonow RO, Carabello B, de Leon AC, et al. ACC/AHA guidelines for the management of valvular disease. J Am Coll Cardiol 1998;32:1486-588.

8 Truninger K, Attenhofer Jost CH, Seifert B, et al. Long term follow up of prosthetic valve endocarditis: what characteristics identify patients who were treated successfully with antibiotics alone? Heart 1999;82:714-20.

9 Durack DT, Lukes AS, Bright DK. New criteria for diagnosis of infective endocarditis: utilization of specific echocardiographic findings. Am J Med 1994;96:200-9.

10 Di Salvo G, Habib G, Pergola V, et al. Echocardiography predicts embolic events in infective endocarditis. J Am Coll Cardiol 2001;37:1069-76.

11 Lytle BW, Priest BP, Taylor PC, et al. Surgical treatment of prosthetic valve endocarditis. J Thorac Cardiovasc Surg 1996;111:198-210.

12 Strandbridge TN, Isalska BJ. Aspects of prosthetic valve endocarditis. J Infect 1997;35:1-6.

13 Piper C, Körfer R, Horskotte D. Prosthetic valve endocarditis. Heart 2001;85:590-3.

14 Vlessis AA, Hovaguimian $\mathrm{H}$, Jaggers J, et al. Infective endocarditis: ten-year review of medical and surgical therapy. Ann Thorac Surg 1996;61:1217-22.

15 Piehler JM, Blackstone EH, Bailey KR, et al. Reoperation on prosthetic heart valves: patient specific estimates of in-hospital events. J Thorac Cardiovasc Surg 1995; 109:30-48.

16 Glazier JJ, Verwlighen JO, Donaldson RM, et al. Treatment of complicated prosthetic aortic valve endocarditis with annular abscess formation by homograft aortic root replacement. J Am Coll Cardiol 1991;17:1177-82.

17 Gordon SM, Serkey JM, Longworth DL, et al. Early onset prosthetic valve endocarditis: the Cleveland Clinic experience 1992-1997. Ann Thorac Surg 2000;69:1388-92.

18 Yu VL, Fang GD, Keys TF, et al. Prosthetic valve endocarditis: superiority of surgical valve replacement versus medical therapy only. Ann Thorac Surg 1994; 58:1073-7.

19 Horskotte D, Körfer R, Loogen F, et al. Prosthetic valve endocarditis: clinical findings and management. Eur Heart $J$ 1984;5(suppl C):117-22

20 Chirouze C, Cabell CH, Fowler VG, et al. Prognostic factors in 61 cases of Staphylococcus aureus infective endocarditis from the International Collaboration on Endocarditis Merged Database. Clin Infect Dis 2004;38:1323-7.

21 Anon. Task force on infective endocarditis of the European Society of Cardiology. Guidelines on prevention, diagnosis and treatment of infective endocarditis. Eur Heart J 2004;25:267-76.

22 Fowler VG, Sexton DJ. The role of valve replacement in the treatment of prosthetic valve endocarditis. Clin Infect Dis 1998;26:1310-1.

\section{IMAGES IN CARDIOLOGY}

\section{Bulky thrombus associated with patent foramen ovale}

A 79 year old woman was admitted for an episode of left facial paralysis and dysarthria which lasted several minutes. Her history included hypertension which was being treated with valsartan.

At admission, no cardiovascular or neurological abnormalities were detected by physical examination, ECG, and carotid ultrasonography, and the only laboratory abnormalities were a fibrinogen concentration of $4.5 \mathrm{~g} / \mathrm{l}$ (normal $<4 \mathrm{~g} / \mathrm{l}$ ), and a blood creatinine concentration of $112 \mu \mathrm{mol} / \mathrm{l}$ (normal $<100 \mu \mathrm{mol} / \mathrm{l}$ ). An emergency brain computed tomographic (CT) scan revealed a right thalamic and a left parietal lacune. Transthoracic echocardiography-complicated by weak echogenicity-detected major mitral insufficiency with mild dilation of the left atrium. Transoesophageal echocardiography revealed discrete left ventricular hypertrophy, voluminous mitral insufficiency as a result of prolapse of the large valve, moderate right atrial dilation, small aortic atheroma, patent foramen ovale with an aneurysm of the interatrial septum, and a $21 \times 13 \mathrm{~mm}$ thrombus attached to the right atrial side of the septum (panel). Vitamin K antagonist treatment was started. Follow up echocardiography carried out three weeks later showed that the thrombus had shrunk (to $12 \times 12 \mathrm{~mm}$ ). Aspirin (75 mg per day) was added to the anticoagulant regimen and the patient is currently free of neurological symptoms.

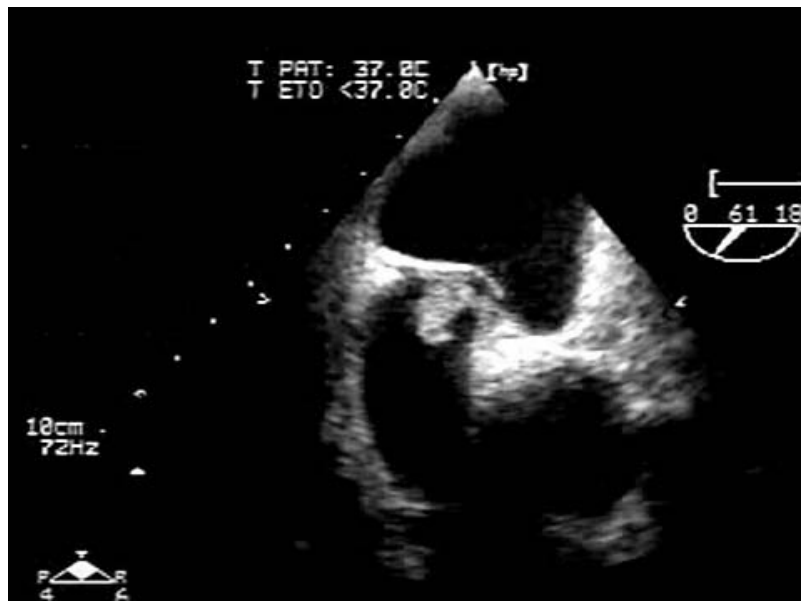

Transoesophageal echocardiography showing a $21 \times 13 \mathrm{~mm}$ thrombus attached to the right atrial side of the septum, associated with patent foramen ovale and an aneurysm of the interatrial septum.

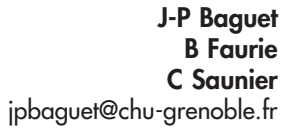

C Saunier ipbaguet@chu-grenoble.fr 